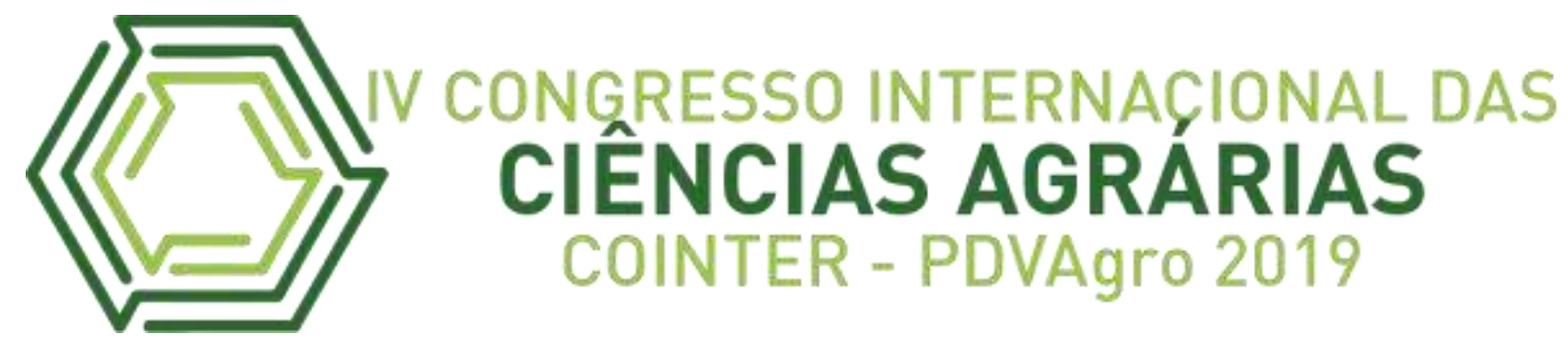

\title{
OCUPAÇÃO DO CERRADO NO MUNICÍPIO DE URUÇUÍ-PI
}

OCUPACIÓN DEL CERRADO EN LA CIUDAD DE URUÇUÍ-PI

OCCUPATION OF THE CERRADO IN THE CITY OF URUÇUÍ-PI

\begin{abstract}
Apresentação: Comunicação Oral
Miguel Antonio Rodrigues ${ }^{1}$; Hercules Elísio da Rocha Nunes Rodrigues²; Tyago Henrique Alves Saraiva Cipriano ${ }^{3}$; Kaio de Sá Araújo ${ }^{4}$; Dayonne Soares dos Santos ${ }^{5}$
\end{abstract}

DOI: https://doi.org/10.31692/2526-7701.IVCOINTERPDVAgro.2019.0027

\section{Resumo}

A partir de pesquisas realizadas com amostras do solo do Cerrado Piauiense, bem como a correção deste, foi possível introduzir culturas como soja e algodão, as quais possibilitaram a implantação e crescimento do Agronegócio nesse território. Nesse cenário, os latifundiários do Sul e Sudeste do país passaram a investir no Cerrado Piauiense. Essa pesquisa tem como objetivo diagnosticar os impactos da Biotecnologia na Agricultura do município de Uruçuí-PI, considerando o Tripé da Sustentabilidade. O estudo foi realizado através de pesquisas bibliográficas especializadas na temática, associadas à coleta de dados e informações de natureza primária obtidos nas Unidades Produtoras Agrícolas do recorte proposto. A exploração da biotecnologia foi fundamental para a expansão desse cultivo. Após confirmação da viabilidade do cultivo de grãos em larga escala no município de Uruçuí, houve especulação crescente das terras localizadas nesse território. Atualmente os produtores preferem o cultivo de sementes transgênicas em detrimento do uso do modelo convencional, pois aquelas apresentam menor vulnerabilidade e, portanto, diminui a necessidade de aplicação de fungicida, mesmo as sementes convencionais sendo mais acessíveis, ao se fazer uma avaliação da viabilidade econômica, os resultados direcionam para a escolha das sementes geneticamente modificadas. Observou-se que não há uma preocupação ou análise do

\footnotetext{
${ }^{1}$ Professor Mestre do curso de Engenharia Agronômica, Instituto Federal do Piauí - campus Uruçuí, e-mail: miguel.rodrigues@ifpi.edu.br

${ }^{2}$ Acadêmico do curso de Bacharelado em Engenharia Agronômica, Instituto Federal do Piauí - Campus Uruçuí, e-mail: herculeselisio@hotmail.com

${ }^{3}$ Acadêmico do curso de Licenciatura em Ciências Biológicas, Instituto Federal do Piauí - Campus Uruçuí, email: tyagohenrique98@gmail.com

4 Aluno do curso Técnico em Agropecuária, Instituto Federal do Piauí - Campus Uruçuí, e-mail: kaiosa@hotmail.com

${ }^{5}$ Professor Mestre do curso de Engenharia Agronômica, Instituto Federal do Piauí - campus Uruçuí, e-mail: dayonnesoares@ifpi.edu.br
} 
valor ambiental nas respostas dos agricultores, eles utilizam os fatores quantitativos como critério para a escolha da modalidade de cultivo. Constatou-se, ainda, que os empreendedores rurais que cultivam grãos em larga escala no município de Uruçuí tem sua origem em outros estados brasileiros, mostrando uma ocupação exógena do território em estudo.

Palavras-Chave: Biotecnologia, latifundiários, viabilidade econômica.

\begin{abstract}
Resumen
A partir de la investigación realizada con muestras de suelo de Cerrado Piauiense, así como la corrección del mismo, fue posible introducir cultivos como la soja y el algodón, lo que permitió la implementación y el crecimiento de los agronegocios en este territorio. En este escenario, los terratenientes del sur y sudeste del país comenzaron a invertir en Cerrado Piauiense. Esta investigación tiene como objetivo diagnosticar los impactos de la biotecnología en la agricultura en el municipio de Uruçuí-PI, considerando el trípode de sostenibilidad. El estudio se realizó a través de una investigación bibliográfica especializada en el tema, asociada a la recolección de datos e información de carácter primario obtenidos en las Unidades de Producción Agrícola del corte propuesto. La explotación de la biotecnología fue fundamental para la expansión de este cultivo. Después de la confirmación de la viabilidad del cultivo de granos a gran escala en el municipio de Uruçuí, se especuló cada vez más sobre las tierras ubicadas en este territorio. Hoy en día, los productores prefieren el cultivo de semillas transgénicas sobre el uso del modelo convencional, ya que son menos vulnerables y, por lo tanto, reducen la necesidad de la aplicación de fungicidas, incluso si las semillas convencionales son más accesibles, al hacer una evaluación de viabilidad económica. , los resultados apuntan a la elección de semillas genéticamente modificadas. Se observó que no hay preocupación o análisis del valor ambiental en las respuestas de los agricultores, ellos usan factores cuantitativos como criterio para elegir el modo de cultivo. También se descubrió que los empresarios rurales que cultivan granos a gran escala en el municipio de Uruçuí tienen su origen en otros estados brasileños, lo que demuestra una ocupación exógena del territorio en estudio.
\end{abstract}

Palabras Clave: Biotecnología, propietarios, viabilidad económica.

\begin{abstract}
From research carried out with soil samples of Cerrado Piauiense, as well as its correction, it was possible to introduce crops such as soybean and cotton, which allowed the implementation and growth of agribusiness in this territory. In this scenario, the landowners of the South and Southeast of the country began to invest in Cerrado Piauiense. This research aims to diagnose the impacts of biotechnology on agriculture in the municipality of Uruçuí-PI, considering the Sustainability Tripod. The study was carried out through bibliographic research specialized in the subject, associated with the collection of data and information of primary nature obtained in the Agricultural Production Units of the proposed cut. The exploitation of biotechnology was fundamental for the expansion of this crop. After confirmation of the viability of large-scale grain cultivation in the municipality of Uruçuí, there was increasing speculation of the lands located in this territory. Nowadays producers
\end{abstract}


prefer the cultivation of transgenic seeds over the use of the conventional model, since they are less vulnerable and, therefore, reduce the need for fungicide application, even if the conventional seeds are more accessible, when making an economic viability assessment. , the results point to the choice of genetically modified seeds. It was observed that there is no concern or analysis of environmental value in the responses of farmers, they use quantitative factors as a criterion for choosing the mode of cultivation. It was also found that rural entrepreneurs who grow large-scale grain in the municipality of Uruçuí have their origin in other Brazilian states, showing an exogenous occupation of the territory under study.

Keywords: Biotechnology, landowners, economic viability..

\section{Introdução}

Fazem parte do Cerrado Piauiense os Municípios de Bom Jesus, Baixa Grande do Ribeiro, Uruçuí, Bertolínia, Santa Filomena, Gilbués, Currais, Ribeiro Gonçalves, Sebastião Leal, Antônio Almeida, Marcos Parente, Porto Alegre do Piauí, Monte Alegre, Palmeira do Piauí, Manoel Emídio, Barreiras do Piauí, Corrente, São Gonçalo do Gurguéia, Redenção do Gurguéia, Elizeu Martins, Colônia do Gurgueia, Pavussu, Cristino Castro, Alvorada do Gurguéia e Parnaguá (CEPRO - Fundação Centro de Pesquisas Econômicas e Sociais do Piauí, 2011).

Entretanto, os municípios que mais se destacaram no agronegócio são Uruçuí, Bom Jesus, Baixa Grande do Ribeiro e Ribeiro Gonçalves (Figura 01).

O maior produtor piauiense de soja é Baixa Grande do Ribeiro, com 675.252 toneladas colhidas, seguido de Uruçuí, com 575.627 toneladas, que antecede o vizinho Ribeiro Gonçalves, com 263.316 toneladas, e Bom Jesus, com 245.114 toneladas. Na figura 1, 
apresenta-se os dez maiores produtores de soja do estado do Piauí:

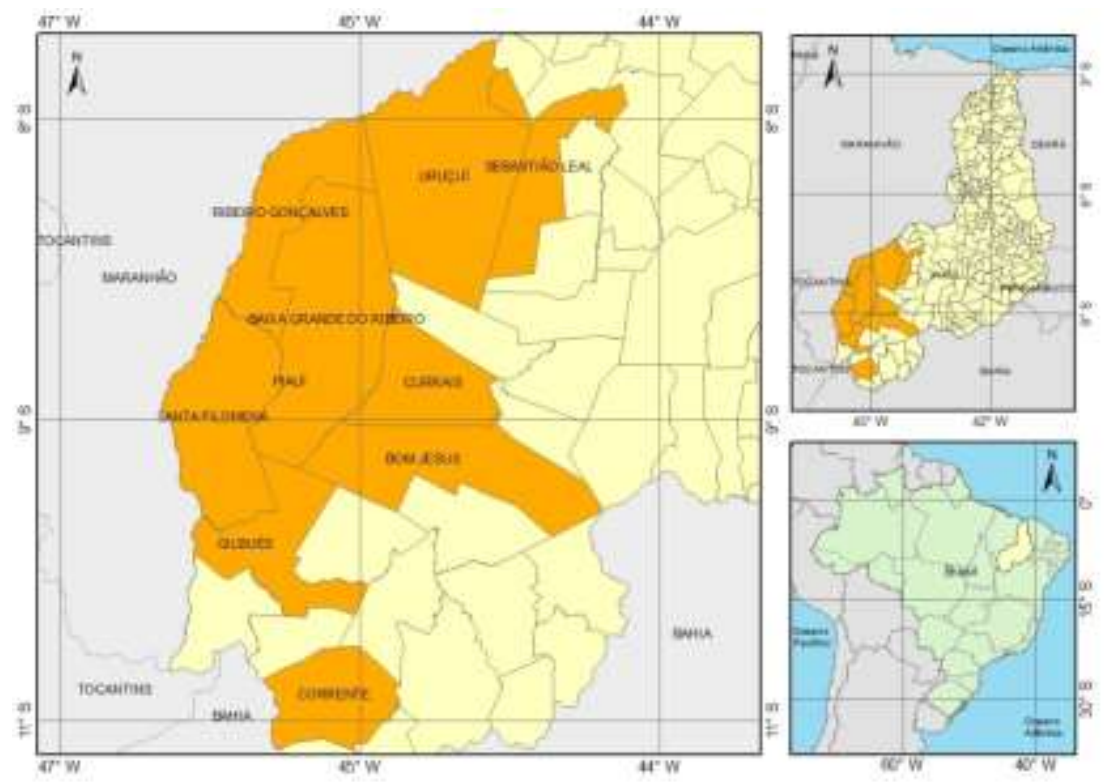

Figura 01: Principais municípios produtores de soja do Cerrado Piauiense.

Fonte: Elaborado pelos autores (2018).

De acordo com a Embrapa (2015), no Estado do Piauí, a região do Cerrado onde há prática do Agronegócio engloba 04 Microrregiões (Alto médio Gurguéia, Alto Parnaíba Piauiense, Chapadas do Extremo Sul Piauiense e Bertolínia, 33 Municípios e 8.204.588 ha, ocupando $11 \%$ da área total.

Considerando a relevância quantitativa da abrangência dessa área, é que se propõe buscar alternativas com vista à melhoria da eficiência produtiva e ampliação do que se explora a outras camadas sociais do território.

A soja foi uma das culturas que apresentaram crescimentos mais expressivos no cultivo e no segmento agroindustrial na segunda metade do século $\mathrm{XX}$ no Brasil, o que justifica sua importância econômica para o país (BARBOSA; ASSUMPÇÃO, 2001).

A região Sul do estado do Piauí hoje é considerada como uma das mais novas fronteiras agrícolas do País, sendo que a produção de soja piauiense vem impulsionando o crescimento da produção agrícola no setor do agronegócio. Haja vista que o aumento de sua produção obtido em 2011 teve acréscimo 31,73\% em relação à safra de 2010, e o aumento da área foi apenas de 11,81\%. As exportações do Piauí também foram afetadas de forma positiva em 2011, atingindo US\$164.346.156, incremento de 27,22\% em relação ao ano anterior. Um dos produtos que apresentaram maior destaque foi a Soja que proporcionou US\$ 90.923.204 em exportações no ano de 2011 para o setor do agronegócio (CEPRO - Fundação Centro de 
Pesquisas Econômicas e Sociais do Piauí, 2012), principalmente devido ao uso de transgênicos.

Transgênicos ou organismos geneticamente modificados são produzidos por meio da transferência de genes de um ser vivo para outro, geralmente de espécies diferentes, como quando a soja recebe genes de vírus, bactérias ou outros organismos (GREENPEACE, 2012).

Quando organismos são geneticamente modificados, um pacote de genes é introduzido, incluindo uma sequência promotora para ativar o gene de interesse (que faz uma planta produzir uma proteína tóxica a insetos ou ser tolerante a um herbicida, por exemplo) e o DNA da sequência terminal, que indica onde é o fim do pacote genético (GREENPEACE, 2012).

Nesse estudo, o problema da pesquisa volta-se parra responder a questionamentos como: Como se deu a ocupação do Cerrado no município de Uruçuí-PI, a partir da implantação de projetos agrícolas de produção em larga escala? Dessa forma, buscou-se descrever os Impactos da Biotecnologia na Agricultura do Município de Uruçuí, com vista a orientação dos produtores para a busca dos meios mais eficientes de produção em grande escala, bem como a necessidade de se avaliar os efeitos que podem causar ao meio ambiente. Nessa perspectiva, buscou-se especificamente: caracterizar o perfil dos produtores agrícolas em nível empresarial do município de Uruçuí-PI; mensurar os níveis de utilização de variáveis advindas da Biotecnologia na agricultura em grande escala do Cerrado Piauiense; conhecer a trajetória de adoção de práticas de uso de Biotecnologia dos produtores agrícolas do recorte geográfico em estudo.

\section{Fundamentação Teórica}

Para Tostes (2005, p.02), as políticas, as estratégias e as iniciativas de intervenção formuladas pelos diversos setores trouxeram o enfoque do desenvolvimento sustentável a ser aplicado no âmbito do planejamento urbano e rural, sendo, mesmo, o balizador de tal planejamento. Desta maneira, nota-se a preocupação com o equilíbrio social, procurando elevar as condições de vida da população, colocando o desenvolvimento econômico como condição fundamental para que isso ocorra em conjunto com as necessárias condições e processos de preservação ambiental.

De acordo com Mendes (2007), o atual modelo de crescimento econômico gerou enormes desequilíbrios; se por um lado, nunca houve tanta riqueza e fortuna no mundo, por outro lado a miséria, a degradação ambiental e a poluição aumentam dia-a-dia. Assim, é 
importante que se cultive a ideia de sustentabilidade, buscando conciliar desenvolvimento econômico com preservação ambiental e, ainda, a minimização da pobreza. Nessa perspectiva, a Biotecnologia pode ser citada como uma alternativa de busca de inserção econômica para aqueles cuja produção agrícola não vem dando condições para projetar uma dinâmica eficiente na atividade.

Com a Biotecnologia moderna, tornou-se possível adotar uma agricultura mais eficiente, com as novas descobertas de melhoramento genético vegetal, possibilitando que as culturas tradicionais fossem substituídas por cultivares melhoradas e plantas transgênicas, com vista a aumentar a produtividade da cultura para suprir a demanda de alimentos (LEITE, 2013). Para essa autora, no cenário mundial, existem duas formas de proteção para a produção de variedades de vegetais, quais sejam: a sui generis (o objeto possui certos requisitos e limitações como: a novidade, distinguibilidade, homogeneidade, estabilidade) e a patente, sendo aquela a que se pratica no Brasil.

Os efeitos de Organismo Geneticamente Modificados no meio ambiente devem ser sempre estudados e acompanhados, porém o potencial de plantas modificadas podem ter papel importante na revitalização da microbiota do solo, recuperando a fertilidade e suas propriedades físico-químicas, o que torna a agricultura uma atividade menos impactante ao meio ambiente (ANDRADE, 2005). Assim, faz-se necessário analisar tais sistemas e observar quais os efeitos de proteção que possam ser benéficos para os agricultores e para os consumidores de modo geral, haja vista que a utilização dessa ferramenta deve ser feita de forma otimizada, maximizando lucros e minimizando os cursos de produção.

Segundo o Ministério do meio Ambiente MMA (2018), o Cerrado é o segundo maior bioma da América do Sul, ocupando uma área de 2.036.448 km2, cerca de 22\% do território nacional. A sua área contínua incide sobre os estados de Goiás, Tocantins, Mato Grosso, Mato Grosso do Sul, Minas Gerais, Bahia, Maranhão, Piauí, Rondônia, Paraná, São Paulo e Distrito Federal, além dos encraves no Amapá, Roraima e Amazonas.

O Cerrado Piauiense teve ocupação predominantemente até a década de 1990 seguido dos anos compreendidos entre 1991 e 2000. Em períodos anteriores a 1990 a existência do plantio de soja no município Uruçuí-PI possuía um caráter apenas experimental. A produção da commodity soja no Brasil tem se concentrado nas regiões Centro-Oeste do país e vem se expandindo para o Nordeste através dos estados do Maranhão, Piauí e Bahia, além da região Norte, consolidando-se na década de 1990, nas regiões Nordeste e Norte do Brasil, onde 
definiu novas fronteiras (LEAL; FRANÇA, 2010).

Até a década de 1960, os solos dos Cerrados eram considerados improdutivos, visto que seus tipos predominantes são os latossolos vermelho-amarelo, senis, distróficos, bem drenados e estruturados, profundos, em geral bastante ácidos, com alto teor de alumínio e ferro, sendo considerados pouco férteis para a agricultura do ponto de vista nutricional (EMBRAPA, 2012). Foi através de pesquisas agronômicas realizadas que se identificaram tecnologias capazes de promover a correção da acidez do solo e adubação, entre outros fatores, que se tornou possível a exploração das potencialidades desse bioma.

Historicamente, as terras dos cerrados eram consideradas não propícias para a produção agropecuária, posto que as condições naturais do solo, centrado em relevo plano ou suavemente ondulado, manifestavam solos fracos e ácidos (MONTEIRO; FERREIRA, 2010). Para esses autores, com a constatação desses condicionantes naturais e o interesse pelo setor agrícola na região, processou-se a modernização da produção, que se caracterizou pelo uso da terra como um substrato passível de mudanças, ao utilizar máquinas pesadas e insumos externos aos ecossistemas, com o objetivo de elevar a produtividade e, consequentemente, possibilitar lucros crescentes.

A partir dessa constatação, os solos do cerrado Brasileiro vêm sendo ocupados em proporções cada vez maiores ao longo do tempo, o que tem provocado muitas mudanças no uso da terra e, como consequência, grandes alterações no ambiente e na forma de vida das pessoas que ali habitam. Um dos fatores que motivam a exploração dos cerrados é a produção de soja em grande escala, tendo em vista a existência de potencialidades locais como as condições favoráveis de solo e clima, a possibilidade de associação com outras culturas, de mecanização da produção, do crescimento da agroindústria, da formação de cooperativas na intermediação e comercialização (LEAL; FRANÇA, 2010). Esses fatores, aliados a outros, como mão de obra local barata e o custo da terra insignificante, foram alvos de muitos empreendedores do Sul e do Sudeste do País, pois possuíam poder aquisitivo e domínio de técnicas para explorar essa nova Fronteira Agrícola.

\section{Metodologia}

A metodologia a ser utilizada será de natureza quanti-qualitativa, pois "o termo quantitativo considera tudo o que pode ser mensurável e quantificável”, ou seja, as opiniões e informações podem ser traduzidas em números. Já o qualitativo implica uma partilha densa 
com pessoas, fatos e locais que constituem objetos de pesquisa, para extrair desse convívio os significados visíveis e latentes que somente são perceptíveis a uma atenção sensível (CHIZZOTTI, 2006).

Segundo Bussab e Morettin (2010), o método de Amostragem Aleatória Simples (AAS), é a maneira mais acessível para selecionar uma amostra probabilística de uma população. Assim, a escolha das Unidades Produtoras de soja e milho do município de Uruçuí será realizada com base na AAS a partir da numeração destes em cartões, onde cada número representou uma unidade produtora de grãos, previamente. Esses cartões foram dobrados, inseridos em uma caixa e retirados ao acaso repetitivamente até que se complete o total de 10 , garantindo, assim, a aleatoriedade da amostra.

\section{Resultados e Discussão}

Os resultados ora discutidos são referentes a 10 Unidades Produtoras de grãos do município de Uruçuí-PI, cujo direcionamento voltou-se para a compreensão da viabilidade do uso de biotecnologia para o cultivo de grãos, considerando aspectos estruturais e ambientais.

Sobre a origem dos produtores que atuam na agricultura em larga escala do município de Uruçuí-PI, observou-se que todos eles são de outros estados brasileiros (figura 2), com destaque para o Rio Grande do Sul.

Os investimentos no Cerrado Piauiense do setor partem de produtores do Sul e Sudeste do país, que vieram em busca de melhores condições de produção (REYDON; MONTEIRO, 2006), o que caracterizou um crescimento exógeno, marcado pelo monopólio do setor produtivo por empreendedores externos ao município em estudo.

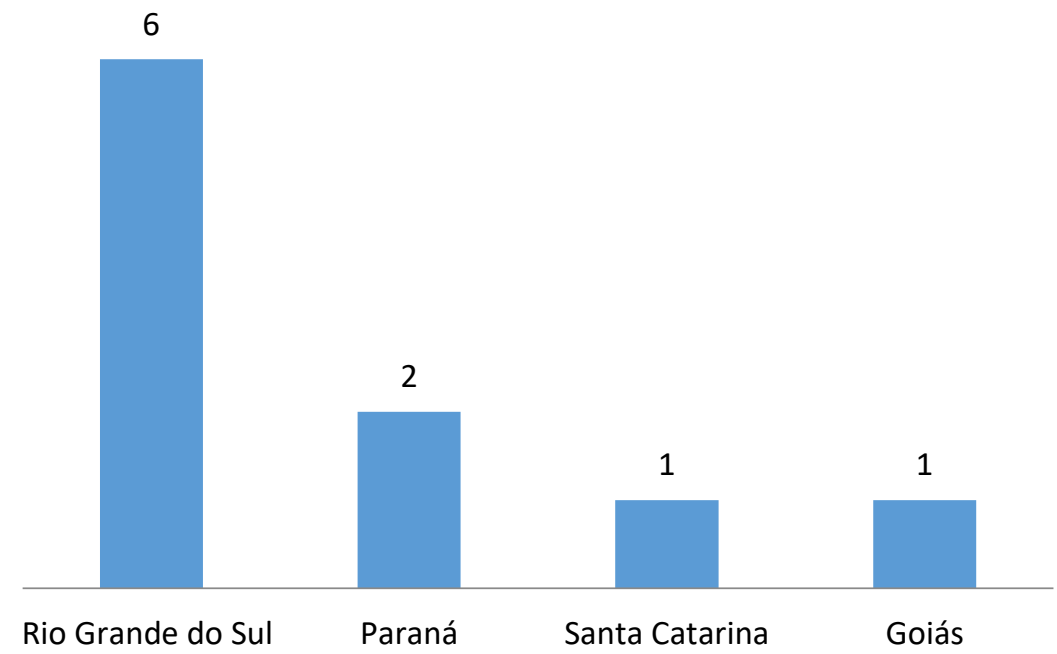


Figura 2: Estado de origem dos produtores de grãos do Município de Uruçuí-PI

Fonte: própria (2018).

Na figura 3, observa-se que a produção de grãos no município caracteriza a prática de latifúndio, tendo em vista que para se constatar a existência da agricultura familiar nessa prática, o limite de hectares nessa produção não poderia ultrapassar 300 hectares, uma vez que de acordo com Araújo (2013), esse limite é de 4 módulos fiscais, que varia de acordo com a densidade demográfica e no caso de Uruçuí o módulo fiscal equivale a 75 hectares.

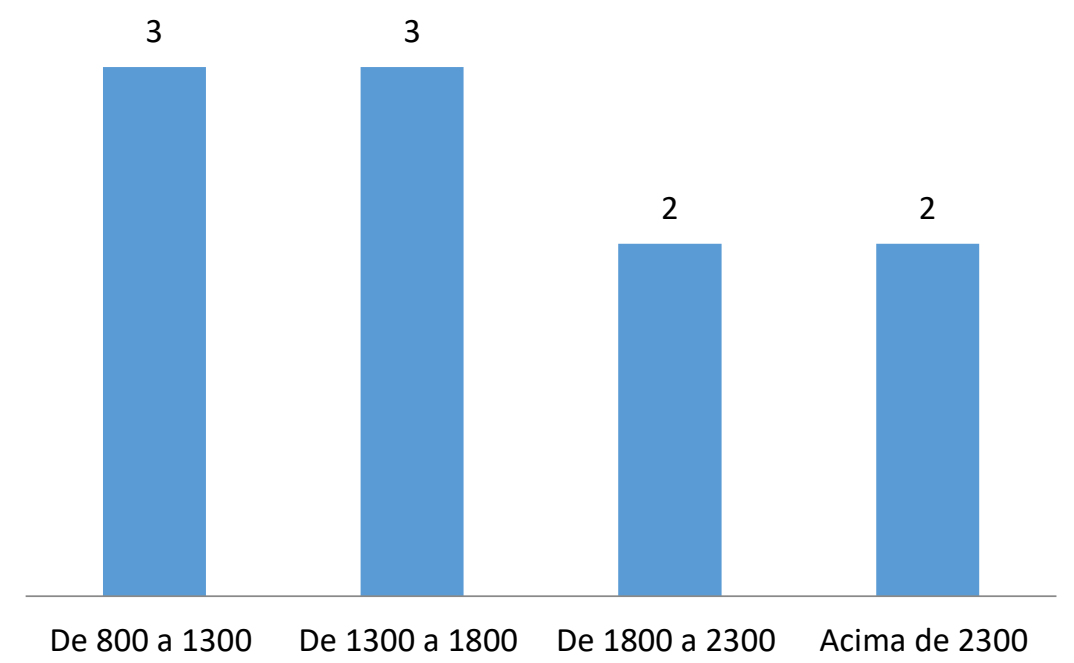

Figura 3: Área total da produção de grãos, em hectare, das Fazendas em análise. Fonte: Própria (2018).

Na figura 4, verifica-se que houve uma especulação dos imóveis rurais, de forma crescente até em 2010. Essa lógica foi constatada também por Rodrigues (2015), que fez um estudo mais detalhado (figura 5) no Distrito Nova Santa Rosa, e quanto às variáveis em análise, destacou-se o período de 1997 a 2009. Os valores foram atualizados, utilizando o preço da saca de soja atual, ou seja, o produtor informou quantas sacas de soja equivaliam ao hectare da terra na época da compra e, fez-se a multiplicação pelo valor da unidade hoje.

Essa especulação aumentava a partir dos sucessos advindos do uso da biotecnologia na agricultura do cerrado piauiense, acarretando na eficiência da produtividade de soja. A partir dessa concentração e do cultivo da soja, o valor do hectare ficou supervalorizado, comparando com o período em que a demanda e as motivações de aquisições não eram predominantes do cenário do agronegócio. 


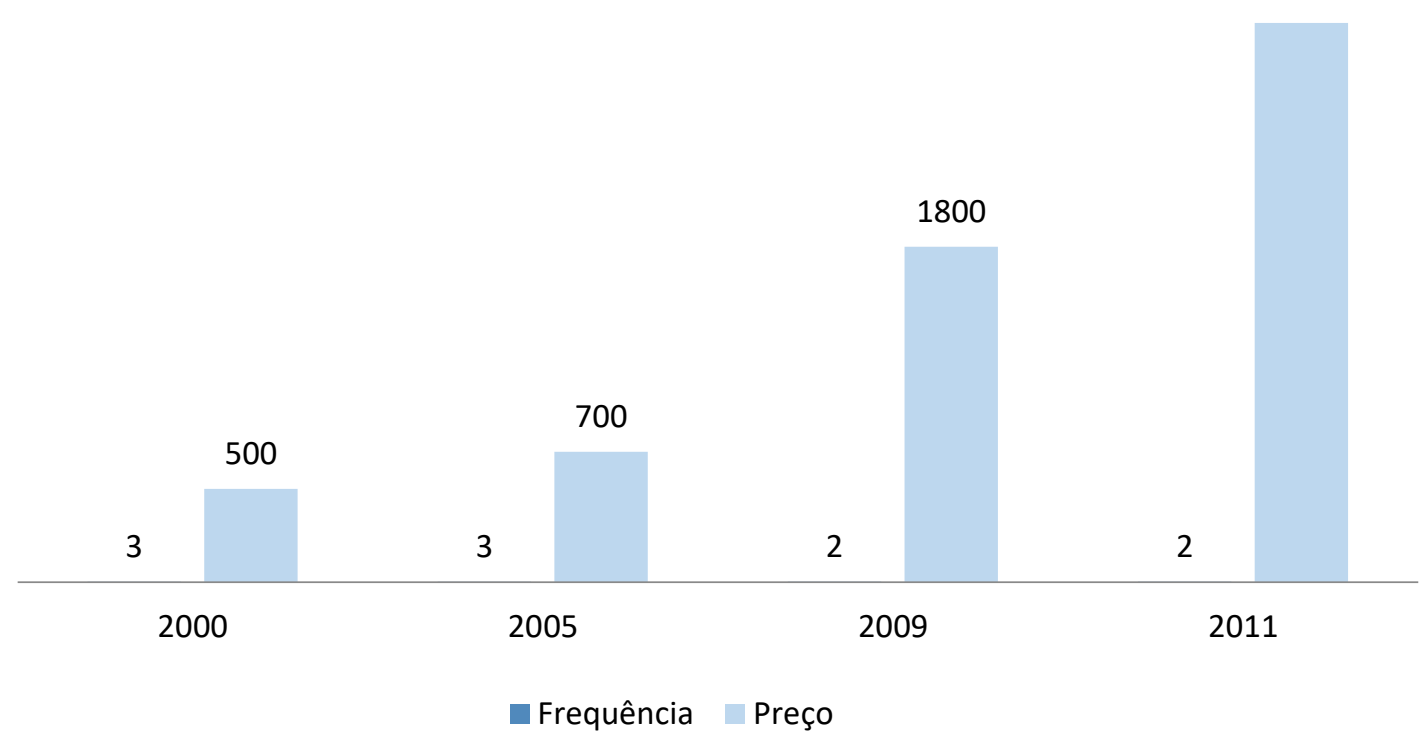

Figura 4: Ano de aquisição da terra e preço médio do hectare nessa época Fonte: Própria (2018)

Ao analisar os resultados apresentados na figura 5, verifica-se que o cultivo convencional de grãos perde espaço para a preferência por uma produção geneticamente modificada, inserida nas práticas de biotecnologia.

A biotecnologia pode ser definida como um conjunto de técnicas de manipulação de seres vivos ou parte destes para fins econômicos, onde se promove a transferência e modificação genética direta, conhecida como engenharia genética ou tecnologia do DNA recombinante, mais a genômica, caracterizando a biotecnologia moderna (SILVEIRA, BORGES; BUAINAIN, 2005). Isso representa um avanço em relação aos métodos mecânicos e químicos propostos pela Revolução Verde, cujo surgimento se deu na década de 1970, representada por um sistema desenvolvido à base de muita tecnologia aplicada à agricultura, que levava em conta o aumento da produção e produtividade agrícola proporcionado por ele solucionaria a questão da fome no mundo (EHLERS, 2008).

Assim, tornou-se possível adotar uma agricultura mais eficiente, com as novas descobertas de melhoramento genético vegetal, possibilitando que as culturas tradicionais fossem substituídas por cultivares melhoradas e plantas transgênicas, com vista a aumentar a produtividade da cultura para suprir a demanda de alimentos (LEITE, 2013). Para essa autora, no cenário mundial, existem duas formas de proteção para a produção de variedades de vegetais, quais sejam: a sui generis (o objeto possui certos requisitos e limitações como: a 
novidade, distingubilidade, homogeneidade, estabilidade) e a patente, sendo aquela a que se pratica no Brasil.

Os efeitos de Organismo Geneticamente Modificados no meio ambiente devem ser sempre estudados e acompanhados, porém o potencial de plantas modificadas podem ter papel importante na revitalização da microbiota do solo, recuperando a fertilidade e suas propriedades físico-químicas, o que torna a agricultura uma atividade menos impactante ao meio ambiente (ANDRADE, 2005). Assim, faz-se necessário analisar tais sistemas e observar quais os efeitos de proteção que possam ser benéficos para os agricultores e para os consumidores de modo geral, haja vista que a utilização dessa ferramenta deve ser feita de forma otimizada, maximizando lucros e minimizando os cursos de produção.

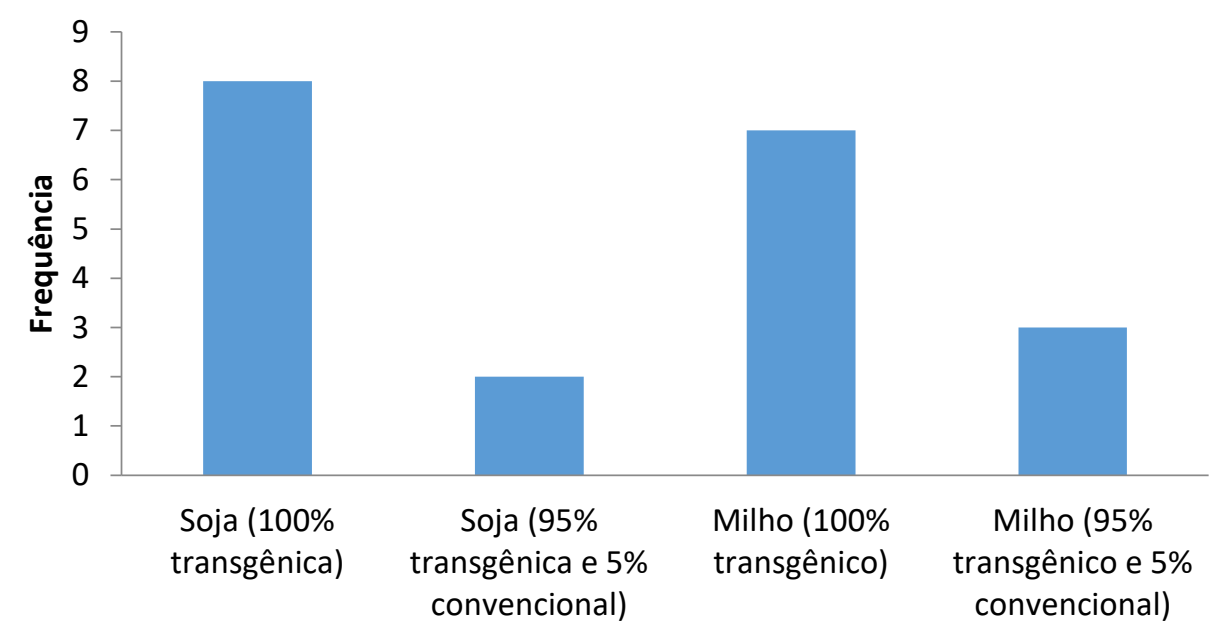

Figura 6: Proporção de cultivo de soja e milho transgênicos x convencionais Fonte: Própria (2018).

Ao serem questionados sobre as motivações da escolha das alternativas geneticamente modificadas ou convencionais, os produtores foram unânimes ao apontarem como vantagens para os geneticamente modificados a menor necessidade de aplicação de fungicida, em comparação com o convencional e, por outro lado, destacaram o alto custo das sementes, pois consideram a modalidade convencional mais acessível, porém apresenta maior necessidade de controle de fungicida e herbicida.

Já sobre o uso de gene de restrição de uso, associado aos motivos da utilização, os produtores afirmaram que fazem a introdução, o que torna as plantas tolerantes ao uso do Roudup Read (glifosado), no controle de ervas daninhas.

Nesse sentido, é importante destacar que essa prática pode colocar a população nas mãos dos produtores que detém essa tecnologia, principalmente em uma situação de escassez 
de alimentos, pois segundo Fernandes (2015), as empresas que já controlavam a produção dos diferentes insumos utilizados na produção agrícola convencional puderam apropriar-se da base primeira da produção, que são as sementes; as sementes híbridas do início da revolução verde trouxeram novo vigor produtivo, mas ao mesmo tempo limitações biológicas para reutilização das sementes; no caso das plantas transgênicas, essa limitação tornou-se restrição imposta por direitos de propriedade intelectual.

Quando o cultivo da cultura é bem difundido na agricultura familiar, como o milho, por exemplo, a modificação genética sobre variedade traz uma consequência negativa: o rompimento de um paradigma quando se pensa nas sementes como bem comum cuidado pelos agricultores que as cultivam e que tem suas origens ancestrais na origem da própria agricultura e da domesticação de espécies (FERNANDES, 2015).

Ao serem questionados sobre os possíveis benefícios trazidos pela biotecnologia para a agricultura do município de Uruçuí-PI, os produtores afirmaram que o aumento na produtividades de grãos adquirida através do potencial genético foi o benefício mais significativo.

O desenvolvimento socioambiental leva em conta a sociedade e o meio ambiente, incentivando a interação e o grau de impacto positivo que a primeira provoca no ambiente e vice-versa. Quando este impacto é negativo, a teoria do Desenvolvimento socioambiental questiona o processo. A sustentabilidade das tecnologias advindas da "Revolução Verde" é questionada por Mueller (1995), quando cita os impactos provocados por estas nos cerrados, conforme segue: a) compactação e impermeabilização dos solos pelo uso intensivo de máquinas agrícolas; b) erosão; c) contaminação por agrotóxicos nas águas, alimentos e animais; d) impactos detrimentais da retirada da vegetação nativa de áreas contínuas extensas; e) assoreamento de rios e reservatórios.

Com a Biotecnologia moderna, além do aumento da produtividade, pode contribuir para a redução dos custos de produção, para a produção de alimentos com melhor qualidade e para a o desenvolvimento de práticas menos agressivas ao meio ambiente (SILVEIRA, BORGES; BUAINAIN, 2005). Isso é possível em culturas que são cultivadas no Cerrado Piauiense, como soja, milho, algodão, entre outras.

Assim, tornou-se possível adotar uma agricultura mais eficiente, com as novas descobertas de melhoramento genético vegetal, possibilitando que as culturas tradicionais fossem substituídas por cultivares melhoradas e plantas transgênicas, com vista a aumentar a 
produtividade da cultura para suprir a demanda de alimentos (LEITE, 2013). Para essa autora, no cenário mundial, existem duas formas de proteção para a produção de variedades de vegetais, quais sejam: a sui generis (o objeto possui certos requisitos e limitações como: a novidade, distinguibilidade, homogeneidade, estabilidade) e a patente, sendo aquela a que se pratica no Brasil.

Os efeitos de Organismo Geneticamente Modificados no meio ambiente devem ser sempre estudados e acompanhados, porém o potencial de plantas modificadas podem ter papel importante na revitalização da microbiota do solo, recuperando a fertilidade e suas propriedades físico-químicas, o que torna a agricultura uma atividade menos impactante ao meio ambiente (ANDRADE, 2005). Assim, faz-se necessário analisar tais sistemas e observar quais os efeitos de proteção que possam ser benéficos para os agricultores e para os consumidores de modo geral, haja vista que a utilização dessa ferramenta deve ser feita de forma otimizada, maximizando lucros e minimizando os cursos de produção.

\section{Conclusões}

Considerando a complexidade que a atividade agrícola incorporou ao longo dos anos, e a "timidez" dos Piauienses no cultivo de grandes áreas, a exploração da biotecnologia foi fundamental para a expansão desse cultivo. Após confirmação da viabilidade do cultivo de grãos em larga escala no município de Uruçuí, houve especulação crescente das terras localizadas nesse território.

Atualmente os produtores preferem o cultivo de sementes transgênicas em detrimento do uso do modelo convencional, pois aquelas apresentam menor vulnerabilidade e, portanto, diminui a necessidade de aplicação de fungicida, mesmo as sementes convencionais sendo mais acessíveis, ao se fazer uma avaliação da viabilidade econômica, os resultados direcionam para a escolha das sementes geneticamente modificadas.

Observou-se que não há uma preocupação ou análise do valor ambiental nas respostas dos agricultores, eles utilizam os fatores quantitativos como critério para a escolha da modalidade de cultivo. Da mesma forma, não se verificou nos depoimentos dos produtores uma visão crítica quanto à possibilidade de os detentores das sementes supervalorizarem em situações de possível escassez de alimentos. 


\section{Referências}

ANDRADE, Galdino. Bioindicadores para uma análise de risco ambiental. Biotecnologia: Ciência \& Meio Ambiente. Número 34 Jan/jun, p. 13-21, 2005.

ARAÚJO, M. J. Fundamentos de agronegócios. 4. ed. São Paulo: Atlas, 2013.

BARBOSA, M. Z. ASSUMPÇÃO, R. Ocupação territorial da produção e da agroindústria da soja no Brasil, nas décadas de 80 e 90 . Informações Econômicas, São Paulo, 31(11):7-16, novembro, 2001.

BRASIL. Ministério do Meio Ambiente. O Bioma Cerrado. Disponível em: https://www.mma.gov.br/biomas/cerrado. Acesso em: 20 jul. 2019.

BRASIL. Ministério do Meio Ambiente (MMA). Agenda 21 Brasileira - Agricultura Sustentável - Produto 3 / Versão final, 1999. Disponível em: www.fea.unicamp.br/docentes/ortega/curso/docfinal.rtf. Acesso em: 23 jun. 2017.

BUSSAB, Wilton O.; MORETTIN, Pedro Alberto. Estatística Básica. 6. ed. - São Paulo: Saraiva, 2010.

CEPRO, Fundação Centro de Pesquisa Econômicas e Sociais do Piauí. Piauí - Conjuntura Econômica, Boletim Anual (2012). CEPRO, 2011, 77 p. Disponível em http://www.cepro.pi.gov.br/download/201204/CEPRO19_88a61d1de4.pdf. Acesso em: 10 set. 2018.

CEPRO, Fundação Centro de Pesquisa Econômicas e Sociais do Piauí. Piauí em números. $8^{\text {a }}$ ed. Disponível em: http://www.cepro.pi.gov.br/download/201104/CEPRO06_aff9b5f5a6.pdf. Acesso em: 23 jul. 2019.

CHIZZOTTI, A. Pesquisa qualitativa em Ciências Humanas e Sociais. Petrópolis: Vozes, 2006. 144p.

EHLERS, E. M. O que é agricultura sustentável. São Paulo: Brasiliense, 2008.

EMBRAPA. Matopiba: Delimitação, Caracterização e desafios e oportunidades para o Desenvolvimento. Disponível em: https://www.embrapa.br/gite/projetos/matopiba/150514_MATOPIBA_MA.pdf. Acesso em 14 out. 2018.

FERNANDES, G. B. Genes como mercadorias: o caso da introdução das sementes transgênicas no Brasil. Dissertação (mestrado). Universidade Federal do Rio de janeiro. Programa de Pós-graduação em História das Ciências e das Técnicas e epistemologia, 2015. Disponível em http://aspta.org.br/wp-content/uploads/2016/02/Dissertacao-GabrielFernandes-Genes-como-mercadorias-2015.pdf. Acesso em 23 set. 2018. 
GREENPEACE. Transgênicos: a verdade por trás do mito. Greenpeace Brasil, São Paulo, SP, 2012. Disponível em: http://www.greenpeace.org.br/transgenicos/pdf/cartilha.pdf. Acesso em: 23 jun. 2018.

Instituto Brasileiro de Geografia e Estatística - IBGE. Descrição agropecuária. Disponível em: http://www.bndes.cnpm.embrapa.br/textos/evolu1.htm. Acesso em: 28 ago. de 2019.

LEAL, Manuela Nunes; FRANÇA, Vera Lúcia Alves. Reestruturação da produção agrícola e organização do espaço agrário piauiense: o agronegócio da commodity soja. B. goiano.geogr. Goiânia, v. 30, n. 2, p. 13-28, jul./dez. 2010.

LEITE, Débora Silva. Biotecnologia e melhoramento das variedades de vegetais: cultivares e transgênico. Veredas do Direito, Belo Horizonte, ?? v.10 ? n.19 ?? p.23-44 ? Janeiro/Junho de 2013.

MENDES, M. C. Desenvolvimento sustentável. Programa Educ@ar, [São Paulo], 2007. Disponível em: <http://educar.sc.usp.br/biologia/textos/m_a_txt2.html>. Acesso em: 25 jun. 2017.

MONTEIRO, Maria do socorro Lira; FERREIRA, Edson Chaves. Ocupação e uso do Cerrado Piauiense:dinâmica do Mercado de Terras. V Encontro Nacional da Anppas 4 a 7 de outubro de 2010 Florianópolis - SC - Brasil.

MUELLER, C. C. Dinâmica, condicionantes e impactos socio-ambientais da evolução da fronteira agrícola no Brasil. Instituto Sociedade, População e Natureza - Documento de Trabalho n.7, 2005. (mimeo).

REYDON, Bastiaan Philip; MONTEIRO, Maria do Socorro Lira. Ocupação do cerrado Piauiense: um processo de valorização Fundiária. In BRASIL. Ministério do Desenvolvimento Agrário. Núcleo de Estudos Agrários e Desenvolvimento Rural. Mercados de terras no Brasil: estrutura e dinâmica / organizadores Bastiaan Philip Reydon. Francisca Neide Maemura Cornélio. Brasília: NEAD, 2006. 444 p.

RODRIGUES, M. A. Caracterização socioeconômica da produção primária da cadeia produtiva da soja no município de Uruçuí-Pi. Dissertação (mestrado) - Universidade Federal do Ceará, Centro de Tecnologia. Programa de Pós-Graduação em Logística e Pesquisa Operacional. Fortaleza, 2015.

SILVEIRA, José Maria Ferreira Jardim da; BORGES, Izaias de Carvalho; BUAINAIN, Antonio Márcio. Biotecnologia e Agricultura: da ciência e tecnologia aos impactos da inovação, 2005. Disponível em < http://www.scielo.br/pdf/spp/v19n2/v19n2a09.pdf>. Acesso em 12 out. 2016.

TOSTES, J. A. Participação da UNIFAP na construção dos planos diretores participativos no Estado do Amapá In: Relatório do I Seminário do Plano Diretor do Município de Laranjal do Jarí.Laranjal do Jarí, 2005. 